\title{
Design of ionic solvents for production of man- made cellulose and silk fibers
}

Keywords: ionic liquids, cellulose solutions, silk fibroin, design of solvents

\section{Introduction}

The making man-made fibers, mainly based on wood pulp, started since the late $19^{\text {th }}$ century. Their industrial production, reaching a maximum in the middle of the twentieth century, was later gradually declining. Due to ecological restrictions the fiber industry began to use the new technology Lyocell instead of the viscose process. In this technology, to solve cellulose, hydrogen sulphide is replaced by $\mathrm{N}$-methylmorpholine-N-oxide (NMMO). Lyocell fiber has higher tensile strength (until $0,55 \mathrm{GPa}$ ) and elastic modulus (until 25GPa) with respect to the viscose fiber (until 0,40 и $10 \mathrm{GPa}$, respectively). However, using NMMO as a direct solvent is dangerous. In fact, already at a temperature slightly above $140^{\circ} \mathrm{C}$ NMMO begins to decompose with the formation of N-methylmorpholine, morpholine and the release of oxygen. This effect leads to formation of explosive mixtures. ${ }^{1,2}$

Therefore, the attention of researchers was attracted by ionic liquids (ILs)-these solvents are thermostable up to $300^{\circ} \mathrm{C}$ and higher, and they are able to dissolve wood pulp well. Being organic salts with a melting point up to $100^{\circ} \mathrm{C}$, ILs practically do not have vapor pressure, and therefore do not pollute the atmosphere. To obtain concentrated cellulose solutions suitable for spinning, the researchers have tried to use ILs based for example on imidazolium, pyridinium and ammonium cations. ${ }^{3}$ At the beginning of the $21^{\text {st }}$ century a new Ioncell process was developed for the processing of wood pulp with the help of ILs. ${ }^{4}$ According to the first information, the properties of new man-made fibers exceed all previously known ones, namely, their tensile strength reaches $0.7-0.8 \mathrm{GPa}$ and elastic modulus approaches to $30 \mathrm{GPa}$. Another promising area of ionic liquids using is the production of new fibers based on silk fibroin. Recycling waste of silk industry, one can create artificial polypeptide fibers with excellent consumer properties. $^{5}$

Ionic liquids have a great advantage with respect to other solvents. It is possible to vary their important technological properties (melting point, thermostability, and dissolving power), which depend on the cation and anion. ${ }^{6-9}$ Note that, on the one hand, during the synthesis of ILs we must provide a technologically justified melting point that can be achieved by increasing the volume of the cation. We can change the number, the mutual position and the length of the substituents of the heterogeneous ring of the cation. On the other hand, an increase in the number and the length of alkyl substituents in the ring implies a decrease in the dissolving power of IL. The choice of the anion is also an important stage in the design of the solvent with the desired properties. When choosing an anion, we should take into account that higher charges on its electron-donor center cause a greater dissolving power of the ionic solvent with respect to natural polymers. This property can be observed experimentally when one measures the Camlet-Taft basicity of the solvent.

We can conclude that the targeted design of the ion pairs allows us to regulate the most important properties of solvents required in

\author{
Volume 5 Issue 2 - 2019
}

\section{Sashina ES}

Saint-Petersburg State University of Industrial Technologies and Design, Institute of Applied Chemistry and Ecology, Russia

\author{
Correspondence: Elena Sashina, Saint-Petersburg State \\ University of Industrial Technologies and Design, Institute of \\ Applied Chemistry and Ecology, Saint-Petersburg, Bolshaya \\ Morskaya, 191186, Russia, Tel +79112155125, \\ Email organika@sutd.ru
}

Received: April 23, 2018 | Published: April 03, 2019

the process of dissolving cellulose and silk fibroin. This fact reveals new perspectives in creating innovative fibers based on fiber-forming polysaccharides, polypeptides and their mixtures.

\section{Acknowledgments}

This work is supported by the Ministry of Education and Science of Russian Federation (project N 4.5718.2017).

\section{Conflicts of interest}

Author declares there is no conflict of interest in publishing the article.

\section{References}

1. Rosenau T, Potthast A, Sixta H, et al. The chemistry of side reactions and byproduct formation in the system NMMO/cellulose (Lyocell process). Progress in polymer science. 2001;26(9):1763-1837.

2. Wendler F, Todi LN, Meister F. Thermostability of imidazolium ionic liquids as direct solvents for cellulose. Thermochimica Acta. 2012;528:76-84.

3. Liebert T, Heinze T. Interaction of ionic liquids with polysaccharides. 5. Solvents and reaction media for the modification of cellulose. BioResources. 2008;3(2):576-601.

4. Sixsta H, Michud A, HauruL, et al. Ioncell-F: A High-strength regenerated cellulose fibre. Nordic Pulp and Paper Research Journal. 2015;30(1):43-57.

5. Sashina ES, Golubikhin YU, Susanin AI. Prospects for producing new biomaterials based on fibroin. Fibre Chemistry. 2015;47(4):253-259.

6. Sashina ES, Kashirskii DA, Janowska G, et al. Thermal properties of 1-alkyl-3-methylpyridinium halide-based ionic liquids. Thermochimica Acta. 2013;568:185-188.

7. Sashina ES, Kashirskii DA, Zaborski M, et al. Synthesis and dissolving power of 1-Alkyl-3-methylpyridinium-based ionic liquids. Russian Journal of General Chemistry. 2012;82(12):1994-1998.

8. Sashina ES, Kashirskii DA, Busygin KN, et. al. Dissolution of cellulose with pyridinium-based ionic liquids: effect of chemical structure and interaction mechanism. Cellulose Chemistry and Technology. 2016;50(2):199-211.

9. Sashina ES. Perspective of using ILs as "green solvents". In: Kuzmina $\mathrm{O}$, Hallett J, editors. Application, purification, and recovery of ionic liquids. Elsevier; 2016:101-159. 